\title{
Recovery of DNA from Footprints in the Snow
}

\author{
Love DaléN ${ }^{1,5}$, Anders Götherström ${ }^{1,2}$, Tomas MeIJER $^{3}$, and Beth Shapiro ${ }^{4}$ \\ ${ }^{1}$ Centro Mixto UCM-ISCIII de Evolución y Comportamiento de Humanos, 28029, Madrid, Spain \\ ${ }^{2}$ Evolutionary Biology Centre, Uppsala University, 752 36, Uppsala, Sweden \\ ${ }^{3}$ Department of Zoology, Stockholm University, S-10691, Stockholm, Sweden. \\ ${ }^{4}$ Department of Zoology, Oxford University, South Parks Road, Oxford OX1 3PS United Kingdom \\ ${ }^{5}$ Present address: School of Biological Sciences, Royal Holloway, University of London, Egham TW20 0EX, United Kingdom; \\ corresponding author email: Love.Dalen@rhul.ac.uk.
}

Dalén, Love, Anders Götherström, Tomas Meijer, and Beth Shapiro. 2007. Recovery of DNA from footprints in the snow. Canadian Field-Naturalist 121(3): 321-324.

The recovery of trace amounts of DNA has been demonstrated to be a reliable tool in conservation genetics and has become a key component of modern forensic casework. To date, genetic data have been successfully recovered from a variety of sources, including biological fluids, faeces, clothing, and even directly from fingerprints. However, to our knowledge and despite their widespread occurrence and clear potential as a source of DNA, genetic information has not previously been recovered directly from footprints. Here, we extract and amplify mitochondrial DNA from a snow footprint, <48-hours old, made by a Swedish Arctic Fox (Alopex lagopus). Our results demonstrate that it is possible to recover sufficient DNA from recent footprints to accurately type the source of the print, with implications for conservation biology and forensic science.

Key Words: Arctic Fox, Alopex lagopus, Red Fox, Vulpes vulpes, trace DNA, conservation biology, forensics.

Both conservation and forensic genetics rely on the ability to retrieve data from material containing only minute amounts of DNA. In forensic studies, key data are often generated from small amounts of biological tissue or liquids recovered from crime scenes (Bond 2007). Conservation geneticists are often interested in applying non-invasive sampling techniques in their research, many of which also target low copy-number biological sources such as hair or faeces (DeSalle and Amato 2004). Methods for recovering trace amounts of DNA have been fine-tuned over the last decade, resulting in the successful amplification of DNA from a variety of sources. For example, previous work has shown that it is possible to recover nuclear DNA from items of worn fabric, such as clothing and the insoles of shoes (Wickenheiser 2002; Bright and Petricevic 2004), and from other fabrics such as bedding (Petricevic, Bright, and Cockerton 2006). Hair shafts and faeces (Kohn and Wayne 1997) from humans, animals, and even ancient specimens (e.g., Higuchi et al. 1988; Gilbert et al. 2004; Pfeiffer et al. 2004; McNevin et al. 2005), fingernails and fingernail scrapings (e.g., Oz and Zamir 2000), and latent fingerprints (e.g., van Oorschot and Jones 1997; Alessandrini et al. 2003; Balogh et al. 2003) have also been shown to be good sources of both mitochondrial DNA (mtDNA) and nuclear DNA.

It is well known that DNA survival is affected by ambient temperature, with the greatest probability of survival occurring in locations with constant low temperatures (Smith et al. 2003). It is therefore conceivable that should biological material be deposited in ice or snow this frozen environment would provide ideal conditions for DNA survival. Potential sources of DNA in ice or snow include shed cells, hair, and biological fluids. However, previous attempts to isolate DNA from randomly selected patches of ice and snow have shown that DNA is rare in the general environment (Hansen and Willerslev 2002). Nonetheless, if it were possible to identify patches in which DNA is concentrated, the combination of cold preservation and the purity of the sample should make these patches an excellent source of genetic information.

The ability to amplify DNA from fingerprints has shown that a few shed skin cells are sufficient for genetic typing. Footprints made by people or animals should therefore be equally viable sources of DNA; however, the nature of the location of footprints (on the ground, mixed with myriad other genetic data) has made this hypothesis difficult to test. Footprints made in snow, however, are unlikely to be contaminated by other sources of DNA or chemical inhibitors. Here, we investigate whether it is possible to recover DNA directly from animal footprints made in snow, and discuss the potential of such an approach for forensic science and conservation biology.

\section{Materials and Methods}

Six samples from fresh $(<48 \mathrm{~h}$ old) fox tracks were collected in Jämtland County, Sweden, during the winter in 2006. Samples were taken from different tracks, so as to minimise the risk of sampling the same individual twice. Each imprint was carefully excavated from the snow using sterile equipment and put into 50 $\mathrm{ml}$ Falcon tubes. Three additional samples were taken from undisturbed snow, for use as negative controls. Due to the possibility of low DNA yields from footprints, and ensuing risk of contamination, the DNA extractions were done in a dedicated ancient DNA 

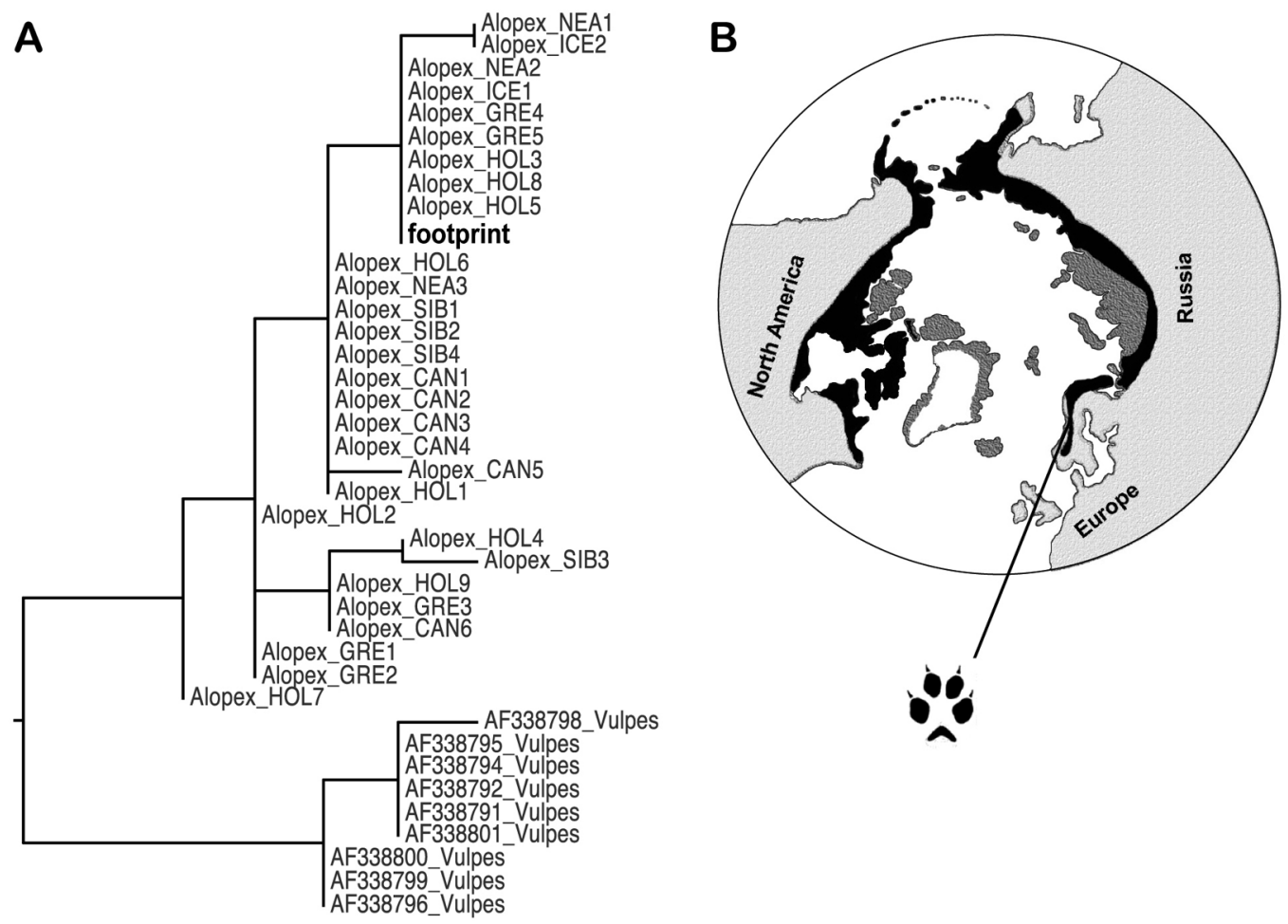

FIGURE 1. (A) Maximum liklihood tree describing the relationships between mitochondrial DNA sequences from Arctic Foxes, Red Foxes, and that recovered from the footprint in central Sweden. Details of the phylogenetic analysis and statistical support are given in the text. (B) Map showing the Holarctic distribution of the two species of fox. Lighter and dark grey shading indicates the distribution of the Red Fox and Arctic Fox, respectively, and black shading indicates where the two ranges overlap. The line indicates the location in Sweden from which the footprints were recovered.

facility in Madrid, Spain. The samples were concentrated using $15 \mathrm{ml}$ Amicon filters (Millipore Massachusetts, USA) and extracted from the resulting filtrate following the protocol by Yang et al. (1998), as modified by Svensson et al. (2007). An approximately 150 base pair (bp) fragment of the mitochondrial control region was amplified using primers Pex3F and H3R (Dalén et al. 2007). Resulting PCR products were sequenced using the Big Dye Terminator v3.1 Cycle Sequencing Kit (Applied Biosystems, California, USA) and analysed on an Applied Biosystems $3730 x 1$ sequencer following the manufacturer's instructions.

Previously published Arctic Fox (Alopex lagopus) and Red Fox (Vulpes vulpes) mitochondrial DNA sequences covering the length of the 150-bp amplifid fragment were collected from GenBank (accession numbers AF338791-AF338792, AF338794-AF338796, AF338 798-AF338801, AY321120-AY321148) and aligned by eye. A Maximum Likelihood (ML) phylogenetic analysis was performed using the program
PAUP v4.10b (Swofford 1999). An HKY model of nucleotide substitution was assumed, so as to allow for different rates of transitions and transversions along the sequences. Starting trees were generated by neighbor-joining (NJ), from which subsitution parameters were estimated and fixed. Heuristic searches were then performed using the estimated substitution parameters and SPR branch swapping. Substitution parameters were then re-estimated from the most likely trees and the analysis was repeated. Figure 1 shows the resulting ML tree describing the relationship of the sequence amplified from the footprint with Arctic and Red foxes. The two clades are separated by bootstrap (100 full heuristic runs, with starting trees generated by $\mathrm{NJ}$ and NNI branch swapping) support values of $96 \%$.

\section{Results}

Mitochondrial DNA was recovered from one of the six footprints from which snow was collected. While it has been shown recently that DNA can be recovered from faecal and hair samples collected along animal 
tracks (Ulizio et al. 2006), this is the first report of DNA being recovered directly from the tracks themselves. Identification of species from tracks presents an important resource for conservation and management of rare species. In this case, both Arctic and Red foxes inhabit the Swedish mountain tundra, and the footprint could thus have derived from either of the two species. However, the resulting mtDNA sequence showed that the footprint originated from an Arctic Fox (Figure 1) and was identical to one of the three mtDNA haplotypes that exist today in Sweden (Dalén et al. 2005).

\section{Discussion}

While the overall success of this initial study was small, it is worthwhile to note that, in this case, only one footprint was sampled from each track. If this method were to be applied in a forensic or conservation genetics context, it would be reasonable to sample several footprints from the same track, significantly increasing the potential for DNA recovery. While this approach would increase the volume of snow or other substrate from which the biological material must be recovered, modern filtration devices such as those employed in this study make it feasible to concentrate large volumes in relatively little time.

The ability to recover DNA from footprints has implications for many areas of research that rely on the ability to amplify low copy number DNA. For example, DNA from footprints could be used to identify individual carnivores that prey on livestock, or to link animal prints found at a crime scene to a specific individual. In conservation genetics, this method makes it feasible to follow individual movements across a landscape, and to directly establish the dimensions of individual home ranges. Perhaps most importantly, the amplification of DNA from footprints could serve as an additional source of non-invasive sampling, complementing conventional materials such as faeces (Höss et al. 1992), hair (Taberlet et al. 1993) and urine (Valiere and Taberlet 2000), and potentially avoiding many of the problems with inhibition that are associated with these sources of DNA.

\section{Acknowledgments}

LD was funded by a Marie Curie Intra-European Fellowship; BS was funded by the Royal Society. The authors thank the Ministerio de Ciencia y Tecnología in Spain and EU-Life SEFALO+ for financial and logistical support.

\section{Literature Cited}

Alessandrini, F., M. Cecati, M. Pesaresi, C. Turchi, F. Carle, and A. Tagliabracci. 2003. Fingerprints as evidence for a genetic profile: Morphological study on fingerprints and analysis of exogenous and individual factors affecting DNA typing. Journal of Forensic Sciences 48: 586-592.

Balogh, M. K., J. Burger, M. Bender, P. M. Schneider, and K. W. Alt. 2003. STR genotyping and mtDNA sequencing of latent fingerprint on paper. Forensic Science International 137: 188-195.

Bond, J. W. 2007. Value of DNA evidence in detecting crime. Journal of Forensic Sciences 52: 128-136.

Bright, J. A., and S. F. Petricevic. 2004. Recovery of trace DNA and its application to DNA profiling of shoe insoles. Forensic Science International 145: 7-12.

Dalén, L., E. Fuglei, P. Hersteinsson, C. M. O. Kapel, J. D. Roth, G. Samelius, M. Tannerfeldt, and A. Angerbjörn. 2005. Population history and genetic structure of a circumpolar species: the arctic fox. Biological Journal of the Linnean Society 84: 79-89.

Dalén, L., V. Nyström, C. Valdiosera, M. Germonpré, M. Sablin, E. Turner, A. Angerbjörn, J. L. Arsuaga, and A. Götherström. 2007. Ancient DNA reveals lack of postglacial habitat tracking in the arctic fox. Proceedings of the National Academy of Sciences of the United States of America 104: 6726-6729.

DeSalle, R., and G. Amato. 2004. The expansion of conservation genetics. Nature Reviews Genetics 5: 702-712.

Gilbert, M. T. P., A. S. Wilson, M. Bunce, A. J. Hansen, E. Willerslev, B. Shapiro, T. F. G. Higham, M. P. Richards, T. C. O'Connell, D. J. Tobin, R. C. Janaway, and A. Cooper. 2004. Ancient mitochondria DNA from hair. Current Biology 14: R463-R464.

Hansen, A. J., and E. Willerslev. 2002. Perspectives for DNA studies on polar ice cores. Pages 17-29 in The Patagonian Icefields: A Unique Natural Laboratory for Environmental and Climate Change Studies. Edited by G. Casassa, F. Sepúlveda and R. Sinclair. Kluwer Academic/Plenum Press.

Higuchi, R., C. H. Vonberoldingen, G. F. Sensabaugh, and H. A. Erlich. 1988. DNA typing from single hairs. Nature 332: 543-546.

Höss, M., M. Kohn, S. Pääbo, F. Knauer, and W. Schröder. 1992. Excrement analysis by PCR. Nature 359: 199-199.

Kohn, M. H., and R. K. Wayne. 1997. Facts from feces revisited. Trends in Ecology \& Evolution 12: 223-227.

McNevin, D., L. Wilson-Wilde, J. Robertson, J. Kyd, and C. Lennard. 2005. Short tandem repeat (STR) genotyping of keratinised hair - Part 1. Review of current status and knowledge gaps. Forensic Science International 153: 237 246.

Oz, C., and A. Zamir. 2000. An evaluation of the relevance of routine DNA typing of fingernail clippings for forensic casework. Journal of Forensic Sciences 45: 158-160.

Petricevic, S. F., J. A. Bright, and S. L. Cockerton. 2006. DNA profiling of trace DNA recovered from bedding. Forensic Science International 159: 21-26.

Pfeiffer, I., I. Volkel, H. Taubert, and B. Brenig. 2004. Forensic DNA-typing of dog hair: DNA-extraction and PCR amplification. Forensic Science International 141: 149-151.

Smith, C. I., A. T. Chamberlain, M. S. Riley, C. Stringer, and M. J. Collins. 2003. The thermal history of human fossils and the likelihood of successful DNA amplification. Journal of Human Evolution 45: 203-217.

Svensson, E., C. Anderdung, J. Baubliene, P. Persson, H. Malmström, C. Smith, M. Vretemark, L. Daugnora, and A. Götherström. 2007. Tracing genetic change over time with nuclear SNPs in ancient and modern cattle. Animal Genetics 38: 378-383.

Swofford, D. 1999. PAUP* Phylogenetic analysis using parsiomony (*and other methods). Sinaur, Sunderland, Massachusetts. 
Taberlet, P., H. Mattock, C. Duboispaganon, and J. Bouvet. 1993. Sexing free-ranging brown bears Ursus arctos using hairs found in the field. Molecular Ecology 2: 399403.

Ulizio, T. J., J. R. Squires, D. H. Pletscher, M. K. Schwartz, J. J. Claar, and L. F. Ruggiero. 2006. The efficacy of obtaining genetic-based identifications from putative wolverine snow tracks. Wildlife Society Bulletin 34: 13261332.

Valiere, N., and P. Taberlet. 2000. Urine collected in the field as a source of DNA for species and individual identification. Molecular Ecology 9: 2150-2152. van Oorschot, R. A. H., and M. K. Jones. 1997. DNA fingerprints from fingerprints. Nature 387: 767-767.

Wickenheiser, R. A. 2002. Trace DNA: A review, discussion of theory, and application of the transfer of trace quantities of DNA through skin contact. Journal of Forensic Sciences 47: 442-450.

Yang, D. Y., B. Eng, J. S. Waye, J. C. Dudar, and S. R. Saunders. 1998. Technical note: Improved DNA extraction from ancient bones using silica-based spin columns. American Journal of Physical Anthropology 105: 539-543.

Received 8 August 2007

Accepted 15 July 2008 